\title{
Parents of Children With Mental Illness: Exploring the Caregiver Experience and Caregiver-Focused Interventions
}

\author{
Amy N. Mendenhall \& Katherine Mount
}

\begin{abstract}
Serious mental illness in children can significantly impact the parents who care for these children in both positive and negative ways. Caregiver strain and enrichment manifests in all areas of parents' lives, including work, mental and physical health, and social and family relationships. Research has identified numerous predictors of caregiver strain such as severity of child's illness and impairment, race, and social support. These parents need strengths-based, parent-focused interventions to help them care for themselves and their family in a healthy, effective manner. A brief summary describes 4 types of interventions for parents of children with mental illness and the supporting research. Education, support, and skill building are all important components in parent interventions. A parent focus for interventions and research will decrease caregiver strain and create a healthier environment for the entire family.
\end{abstract}

\section{IMPLICATIONS FOR PRACTICE}

- Mental illness in children has significant impact on parents, so clinical intakes should include assessment of parental strain to determine the needs of the entire family in the treatment process.

$\mathbf{M}$ ental illness in children affects more than just the children-it impacts the entire family. Parents become both caregivers, managing the fluctuating moods and behaviors of their children, and case managers, coordinating the services needed by their children. Parent caregivers of children with mental illness struggle to meet the needs of their entire family by balancing the needs of their child, other family members, and themselves. They may face challenges such as financial burden, sibling rivalry, stigma, self-doubt and blame, marital stress, and difficulty accessing services, in addition to dealing with the symptoms their child is experiencing (Commonwealth Institute, 1999). Family caregivers have been described as stressed, with the potential of having more problems than the persons for whom they care (Lefley, 1997).

Family involvement in mental health treatment and service can empower parents to more successfully manage their children's illness and to be educated advocates for their own children and for others, leading to more positive outcomes for the entire family. Children of caregivers who perceived themselves as competent and knowledgeable in one study functioned better than children of caregivers who felt less empowered (Resendez, Quist, \& Matshazi, 2000). Despite the impact mental illness can have on the entire family, many therapeutic approaches do not recognize or address the strengths and needs of the parents or whole family. Families not only struggle with the symptoms and impairment of their child's mental illness but also struggle to get appropriate services from treatment providers (MackinawKoons \& Fristad, 2004). A review of intervention studies for children and adolescents suffering with depression found that only 3 of 14 of the interventions studied included a family component (Kaslow \& Thompson, 1998). The focus has been primarily on the impact mental illness can have on children's functioning in areas such as home, school, and peers, and less literature focuses on how mental illness in children impacts the functioning of those closest to them such as their parents and siblings.

This article reviews the literature on the biopsychosocial impact of mental illness in children on their parents who are acting as caregivers. The review describes the impact of the caregiver experience on various spheres of life, including mental and physical health, work, and social and family relationships, and summarizes the predictors of the presence and nature of caregiver strain as found in previous research. To conclude, the authors describe some of the available parentfocused interventions and supporting research for use with families of children with mental illness.

\section{The Caregiver Experience}

Caring for a loved one who needs additional support because of illness can be a challenging experience fraught with unfamiliar roles, increased responsibilities, and heightened stress. The difficulty associated with these experiences has been referred to as caregiver burden or strain. Caregiver burden has been described as the "presence of problems, difficulties or adverse events which affect the life [lives] of the psychiatric patient's significant other[s]" (Platt, 1985, p. 383). Similarly, caregiver strain has been used to refer to negative consequences, both physical and emotional, that impact caregivers as a result of the additional responsibilities of caring for a loved one who is ill (Heflinger \& Brannan, 2006). The research on caregiver strain and burden focuses mainly on caring for adult children with mental illness, children with chronic illness, or the elderly. Less research focuses on caring for children suffering from mental illness, even though in the general population, approximately $10.7 \%$ of parents feel burdened as a result of the psychiatric symptoms experienced by their children (Angold et al., 1998). Raising a child can be a difficult process, and adding the symptomatology and impairment of mental illness can magnify the stress and strain parents experience. Despite the challenges, some caregivers report positive aspects of caring for their loved ones, referred to as caregiver enrichment, which may enhance the quality of experiences in a family's daily life (Yatchmenoff, Koren, Friesen, Gordon, \& Kinney, 1998). However, caregiver enrichment has been the focus of very little research. 
graphics and quizzes are incorporated into the sessions. Results indicate reductions in anxiety symptoms, and reports from a case review indicate that parents and children were satisfied with this intervention because they were able to complete the sessions at their own pace and at times that were convenient for them (Spence et al.). The Incredible Years training program (Taylor et al., 2008) teaches parents methods for coping with difficult behavior in children with a unique combination of phone calls, e-mails, and home visits, so parents have the convenience of online methods in addition to the advantage of in-person training (Taylor et al.). Parents using this intervention have reported high achievement of the goals outlined by the program.

\section{Interventions Summary}

Despite varying formats, all of these interventions focus on the needs of caregivers of children with mental illness in an effort to enhance caregiver strengths and resources and decrease caregiver strain, therefore improving the health and functioning of the entire family. PEP stresses the importance of education about illness, treatment, and symptom management for caregivers. The various models of psychotherapy use therapeutic techniques to address mental health symptoms and family dynamics. PMT also provides education for caregivers, but it is specifically focused on techniques to manage difficult behavior in children. Technology-based interventions incorporate the growing area of technology into mental health by providing caregivers with alternative options that may be more adaptive to caregivers' busy lives. The common elements across these interventions are education, support, and skill building. Additionally, most of these parent-focused interventions provide flexibility in format and topics addressed with the recognition that parents have varying strengths and needs and may prefer nontraditional options for education and support.

\section{Conclusion}

Raising a healthy child can be challenging but adding the additional roles, worries, and struggles of caring for a child suffering from mental illness can significantly impact numerous areas of a parent's life, including mental and physical health, work, and social and family relationships. If parents are not healthy and supported, they may not be able to provide themselves, their child, and the rest of their family with the best possible care. Also in the midst of these difficulties, parents may simply overlook the enriching aspects of the caregiving experience and the strengths or resources they bring to the experience. As such, initial clinical intakes of children with mental illness should include assessment of caregiver and family strain and enrichment in various areas of life to determine the families' strengths and needs relevant to the treatment process. Social workers are particularly suited to conducting these types of assessments and for working with these families because of the profession's ecological, strengths-based orientation.

Despite the potentially large impact of the caregiver experience, treatment of children with mental illness often focuses on treating the child's symptoms and helping the child cope with his or her illness rather than encouraging strengths and empowering families with the education and resources they need to be effective and healthy caregivers. The interventions described in this article acknowledge that the parents are an integral part of their child's care, and social workers may find these interventions to be an effective addition in working with this population. To successfully incorporate these interventions into their work with families, social workers need to stay up-to-date on the cur- rent evidence-based research, and in order for social workers to do this, additional research and resources for practitioner education and training in the various caregiver-focused interventions are needed. Only a few of the available models for each of the types of interventions are highlighted in this article, and so practitioners should do further research before determining which model may be most appropriate for their clients. When implementation of these full interventions is not possible in clinical settings, social workers may need to deconstruct the intervention to determine which of the caregiver-focused treatment components (e.g., education, support, and skill building) can be successfully incorporated into their treatment planning.

In the physically and emotionally close environment of a family, mental health symptoms and impairment in children can negatively impact everyone around them, and consequently, the negative impact on the family can cycle back to further complicate the child's difficulties. To alleviate family strain, increase caregiver enrichment, and improve chances of child recovery, practitioners working with children with mental illness should incorporate not only caregivers but also siblings and extended family into a family-focused, strengths-based treatment when appropriate. However, social workers should also use their clinical judgment to determine when family members need more help than they can provide as a part of the child's treatment, and in those cases, it is important to have information on hand for caregiver referrals.

Though the primary focus of this article has been on the micro level, there are important implications for social work practice at a macro level as well. Many of the challenges that cause strain in families of children with mental illness are consequences of the shortcomings of the macro environment (e.g., unsympathetic nature of workplace, lack of appropriate child care, failure of the health care system, and widespread stigma against mental illness). By providing educational, strengths-building interventions to families, social workers empower parents to advocate for their own family in their local schools and neighborhood, which in turn may positively affect others in their area who are being impacted by the presence of mental illness in their families. Additionally, social workers can introduce parents to recovery and consumer-based organizations that provide opportunities for support, education, and advocacy, such as the National Alliance on Mental Illness (NAMI; http://www.nami.org).

As professionals, social workers also have the tools and opportunities to advocate for change for families of children with mental illness. In their agencies, social workers can encourage other coworkers to adopt a family-focused, strengths-based framework when working with families, and they can advocate for agency-wide training on evidence-based interventions that align with these values. On the state and national level, social workers can be involved with organizations such as NAMI and the National Association of Social Workers to stay up-to-date on legislative actions that provide opportunities for advocating for change. The stressful nature of parenting a child with a mental illness may be inevitable, but social workers can help by providing parents with the best services and treatment, by empowering parents to identify their strengths and the enrichment in their experiences, and by working side by side with parents and other professionals to advocate for change at a macro level to provide better conditions for families of children with mental illness.

\section{References}

Angold, A., Messer, S. C., Stangl, D., Farmer, E. M. Z., Costello, E. J., \& Burns, B. J. (1998). Perceived parental burden and service use for child and adolescent psychiatric disorders. American Journal of Public Health, 88(1), 75-80. 
Baker, D. B., \& McCal, K. (1995). Parenting stress in parents of children with attention-deficit hyperactivity disorder and parents of children with learning disabilities. Journal of Child and Family Studies, 4(1), 57-68.

Bischoff, R. J., Hollist, C. S., Smith, C. W., \& Flack, P. (2004). Addressing the mental health needs of the rural underserved: Findings from a multiple case study of a behavioral telehealth project. Contemporary Family Therapy: An International Journal, 26(2), 179-198.

Bradley, S. J., Jadaa, D. A., Brody, J., Landy, S., Tallett, S. E., Watson, W.,...Stephens, D. (2003). Brief psychoeducational parenting program: An evaluation and 1-year follow-up. Journal of the Academy of Child and Adolescent Psychiatry, 42, 1171-1178.

Brennan, E. M., \& Brannan, A. M. (2005). Participation in the paid labor force by caregivers of children with emotional and behavioral disorders. Journal of Emotional and Behavioral Disorders, 13, 237-246.

Choate, M. L., Pincus, D. B., Eyberg, S. M., \& Barlow, D. H. (2005). Parent-child interaction therapy for treatment of separation anxiety disorder in young children: A pilot study. Cognitive and Behavioral Disorders, 12(1), 126-135.

Cohen, J. A., Mannarino, A. P., \& Staron, V. R. (2006). A pilot study of modified cognitive behavioral therapy for childhood traumatic grief (CBT-CTG). Journal of the American Academy of Child and Adolescent Psychiatry, 45(12), $1465-1473$.

Commonwealth Institute for Child and Family Studies. (1999). Families on the brink: The impact of ignoring children with serious mental illness. Virginia: National Alliance for the Mentally Ill.

Costin, J., \& Chambers, S. M. (2007). Parent management training as a treatment for children with oppositional defiant disorder referred to a mental health clinic. Clinical Child Psychology and Psychiatry, 12(4), 511-524.

Eyberg, S. M. (1988). Parent-child interaction therapy: Integration of traditional and behavioral concerns. Child and Family Behavior Therapy, 10, 33-46.

Eyberg, S. M., Funderburk, B. W., Hembree-Kigin, T. L., McNeil, C. B., Querido, J. G., \& Hood, K. K. (2001). Parent-child interaction therapy with behavior problem children: One and two year maintenance of treatment effects in the family. Child and Family Behavior Therapy, 23, 1-20.

Friesen, B. J. (1989). National study of parents whose children have serious emotional disorders: Preliminary findings. In A. Algarin, R. M. Friedman, A. J. Duchnowski, K. M. Kutash, S. E. Silver, \& M. K. Johnsons (Eds.), 2nd annual conference proceedings, children mental health services and policy: Building a research base (pp. 36-52). Tampa, FL: Research and Training Center for Children's Mental Health, Florida Mental Health Institute, University of South Florida.

Fristad, M. A. (2006). Psychoeducational treatment for school-aged children with bipolar disorder. Development and Psychopathology, 18, 1289-1306.

Fristad, M. A., Verducci, J. S., Walters, K., \& Young, M. (2009). The impact of multifamily psychoeducational psychotherapy in treating children aged 8-12 with mood disorders. Archives of General Psychiatry, 66(9), 1013-1021.

Greer, F. A., Grey, I. M, \& McClean, B. (2006). Coping and positive perceptions in Irish mothers of children with intellectual disabilities. Journal of Intellectual Disabilities, 10, 231-248.

Heflinger, C. A., \& Brannan, A. M. (2006). Differences in the experience of caregiver strain between families caring for youth with substance use disorders and families of youth with mental health problems. Journal of Child and Adolescent Substance Abuse, 15(3), 83-104.

Hellander, M., Sisson, D. P., \& Fristad, M. A. (2003). Internet support for parents of children with early-onset bipolar disorder. In B. Geller \& M. DelBello (Eds.), Bipolar disorder in childhood and early adolescence (pp. 314-329). New York: Guilford Press.

Kaslow, N. J., \& Thompson, M. P. (1998). Applying the criteria for empirically supported treatments to studies of psychosocial interventions for child and adolescent depression. Journal of Clinical Child Psychology, 27, 146-155.

Kazdin, A. E. (1997). Parent management training: Evidence, outcomes, and issues. Journal of the American Academy of Child and Adolescent Psychiatry, 36(10), 1349-1356.

Kuulasmaa, A., Wahlberg, K., \& Kuusimaki, M. (2004). Videoconferencing in family therapy: A review. Journal of Telemedicine and Telecare, 10(3), 125-129.

Lefley, H. P. (1997). The consumer recovery vision: Will it alleviate family burden? American Journal of Orthopsychiatry, 67(2), 210-219.

Lehmkuhl, H. D., Storch, E. A., Rahman, O., Freeman, J., Geffken, G. R., \& Murphey, T. K. (2009). Just say no: Sequential parent management training and cognitive behavioral therapy for a child with comorbid disruptive behavior and obsessive compulsive disorder. Clinical Case Studies, 8(1), $48-58$

Lopez, M. A., Toprac, M. G., Crismon, M. L., Boemer, C., \& Baumgartner, J. (2005). A psychoeducational program for children with ADHD or depression and their families: Results from the CMAP feasibility study. Community Mental Health Journal, 41, 51-66.
Lukens, E. P., \& McFarlane, W. R. (2004). Psychoeducation as evidence-based practice: Considerations for practice, research and policy. Brief Treatment and Crisis Intervention, 4, 205-225.

Mackinaw-Koons, B., \& Fristad, M. A. (2004). Children with bipolar disorder: How to break down barriers and work effectively together. Professional Psychology: Research and Practice, 35, 481-484.

Marsh, D. T., \& Johnson, D. L. (1997). The family experience of mental illness: Implications for intervention. Professional Psychology: Research and Practice, 28(3), 229-237.

McCabe, K. M., Yeh, M., Lau, A., Garland, A., \& Hough, R. (2003). Racial/ethnic differences in caregiver strain and perceived social support among parents of youth with emotional and behavioral problems. Mental Health Services Research, 5(3), 137-147.

Mendenhall, A. N., Fristad, M. A., \& Early, T. J. (2009). Factors influencing service utilization and mood symptom severity in children with mood disorders: Effects of multifamily psychoeducation groups (MFPGs). Journal of Consulting and Clinical Psychology, 77, 463-473.

Miklowitz, D. J., George, E. L., Axelson, D. A., Kim, E. Y., Birmaher, B., Schneck, C.,...Brent, D. A. (2004). Family-focused treatment for adolescents with bipolar disorder. Journal of Affective Disorders, 82(1), 113-128.

Miklowitz, D. J., Simoneau, T. L., George, E. L., Richards, J. A., Kalbag, A., SachsEricsson, N., \& Suddath, R. (2000). Family-focused treatment of bipolar disorder: 1-year effects of a psychoeducational program in conjunction with pharmacotherapy. Biological Psychiatry, 48, 582-592.

Mohr, W. K., \& Regan-Kubinski, M. J. (2001). Living in the fallout: Parents' experiences when their child becomes mentally ill. Archives of Psychiatric Nursing, 15(2), 69-77.

Murphy, N. A., Christian, B., Caplin, D. A., \& Young, P. C. (2007). The health of caregivers for children with disabilities: Caregiver perspectives. Child: Care, Health and Development, 33(2), 180-187.

Ong, S. H., \& Caron, A. (2008). Family-based psychoeducation for children and adolescents with mood disorders. Journal of Child and Family Studies, 17(6), 809-822.

Pickett, S. A., Vraniak, D. A., Cook, J. A., \& Cohler, B. J. (1993). Strength in adversity: Blacks bear burden better than Whites. Professional Psychology: Research and Practice, 24(4), 460-467.

Platt, S. (1985). Measuring the burden of psychiatric illness on the family: An evaluation of some rating scales. Psychological Medicine, 15, 383-393.

Resendez, M. G., Quist, R. M., \& Matshazi, D. G. M. (2000). A longitudinal analysis of family empowerment and client outcomes. Journal of Child and Family Studies, 9(4), 449-460.

Richardson, L. K., Frueh, B. C., Grubaugh, A. L., Johnson, R. H., Egede, L., \& Elhai, J. D. (2009). Current directions in videoconferencing tele-mental health research. Clinical Psychology, 16(3), 323-338.

Rosenzweig, J. M., Brennan, E. M., \& Ogilvie, A. M. (2002). Work-family fit: Voices of parents of children with emotional and behavioral disorders. Social Work, $47(4), 415-424$.

Rosenzweig, J. M., \& Huffstutter, K. J. (2004). Disclosure and reciprocity: On the job strategies for taking care of business... and family. Focal Point: A National Bulletin on Family Support and Children's Mental Health, 18, 4-7.

Sanders, M. R. (1999). Triple P-Positive Parenting program: Towards an empirically validated multilevel parenting and family support strategy for the prevention of behavior and emotional problems in children. Clinical Child and Family Psychology Review, 2(2), 71-90.

Sanford, M., Boyle, M., McCleary, L., Miller, J., Steele, M., Duku, E., \& Offord, D. (2006). A pilot study of adjunctive family psychoeducation in adolescent major depression: Feasibility and treatment effect. Journal of the American Academy of Child and Adolescent Psychiatry, 45, 386-395.

Scahill, L., Sukhodolsky, D. G., Bearss, K., Findley, D., Hamrin, V., Carroll, D. H., \& Rains, A. L. (2006). Randomized trial of parent management training in children with tic disorders and disruptive behavior. Journal of Child Neurology, 21(8), 650-656.

Schoeder, C. E., \& Remer, R. (2007). Perceived social support and caregiver strain in caregivers of children with Tourette's disorder. Journal of Child and Family Studies, 16(6), 888-901.

Spence, S. H., Donovan, C. L., March, S., Gamble, A., Anderson, R., Prosser, S.,...Kenardy, J. (2008). Online CBT in the treatment of child and adolescent anxiety disorders: Issues in the development of BRAVE-ONLINE and two case illustrations. Behavioural and Cognitive Psychotherapy, 36(4), 411-430.

Stainton, T., \& Besser, H. (1998) The positive impact of children with an intellectual disability on the family, Journal of Intellectual and Developmental Disability, $23,57-70$. 
Taylor, T. K., Webster-Stratton, C., Feil, E. G., Broadbent, B., Widdop, C. S., \& Severson, H. H. (2008). Computer-based intervention with coaching: An example using the Incredible Years program. Cognitive Behaviour Therapy, 37(4), 233-246.

Taylor-Richardson, K. D., Heflinger, C. A., \& Brown, T. N. (2006). Experience of strain among types of caregivers responsible for children with serious emotional and behavioral disorders. Journal of Emotional and Behavioral Disorders, 14, 157-168.

Wagner, S. M., \& McNeil, C. B. (2008). Parent-child interaction therapy for ADHD: A conceptual overview and critical literature review. Child and Family Behavior Therapy, 30(3), 231-356.

Wilder, L., Wasow, M., \& Hatfield, E. (1983). Seeking strengths in families of developmentally disabled children. Social Work, 28, 313-315.

Yatchmenoff, D. K., Koren, P. E., Friesen, B. J., Gordon, L. J., \& Kinney, R. F. (1998). Enrichment and stress and families caring for a child with a serious emotional disorder. Journal of Child and Family Studies, 7(2), 129-145.

Amy N. Mendenhall, PhD, MSW, assistant professor, University of Kansas.

Katherine Mount, BA, clinical research assistant, Ohio State University. Correspondence: amendenhall@ku.edu; School of Social Welfare, University of Kansas, 1545 Lilac Lane, Lawrence, KS 66044.

\section{Your colleagues agree...}

Families in Society is an excellent resource for tools and information about staff training, professional learning, program development, and evaluation services.

"The article on Dine

(Navajo) natural helping

and resilience is an

excellent resource for our

early childhood care and development initiative."

Jaime Apolonio

First Nations Partnership Programs
"The article on foster parent decision-making has been very helpful in providing information and statistics on the effectiveness of recruitment and retention of foster parents."

Melissa Cole

Foster Family-Based Treatment Association

\section{"Because the articles on ethics were so} comprehensive, they were perfect to utilize in our training sessions for over 200 social workers." 